\title{
DESENVOLVIMENTO DAS ACTIVIDADES COMPETITIVAS DAS EMPRESAS NA ÁREA COMERCIAL
}

\author{
Fernando Nascimento *
}

Procurarei dar, no princípio, uma ideia do que é e do que foi a evolução das actividades de Marketing em Portugal que já têm uma longa história.

Deixem-me contar duas historietas: uma do mundo da banda desenhada, a outra de conteúdo mais histórico.

- A primeira tem a ver com um autor de banda desenhada chamado Hergé, o autor das histórias do TinTin. Ele escreveu 20 e tal livros sobre assuntos passados em muitos países diferentes e inventou centenas de personagens. No meio daquela confusão apareceu lá um português que é o senhor Oliveira da Figueira, um comerciante das sete partidas do mundo. É uma figura simpática, que ajuda o herói dessas aventuras, mas é uma figura dedicada ao comércio. Aparentemente Hergé, que recolheu informação sobre " $n$ " povos do mundo, ao olhar para os portugueses apanhou esta nossa faceta comercial e retratou o povo português através desta figura.

Penso que, de certa forma, os Portugueses têm algum jeito inato para o comércio.

- A segunda historieta é que nós somos um povo descobridor, em que a actividade comercial representou algo muito importante na nossa História. É evidente que o pico já foi há 500 anos atrás, mas ao longo da História há vários episódios que reforçam esta ideia. Direi que, nessa altura, tínhamos uma visão moderna do comércio internacional (hoje utilizamos a palavra global, que é uma palavra agora muito em moda). E não se pense que o comércio português era só entre a Metrópole e as colónias: onde quer que estivéssemos, encontrávamos oportunidades de fazer negócio, de uma forma extremamente rentável para ambos os lados.

Estou a lembrar-me da nossa História, dos negócios da seda e da prata que havia no séc. XV e XVI, entre o Japão e a China: os Japoneses não se entendiam com os Chineses e apareceram os intermediários que eram os Portugueses, que organizavam esse comércio, baseados em Macau.

Os Portugueses iam buscar seda à China e vendê-la ao Japão e buscar prata ao Japão e vendê-la à China. Portanto, não precisávamos de uma Metrópole para realizar negócios.

\footnotetext{
* Faculdade de Ciências Económicas e Empresariais da Universidade Católica Portuguesa.
} 
Tínhamos como concorrentes os Espanhóis que estavam baseados em Manila, mas estes tinham um problema: não tinham acesso à corte japonesa, de modo que traziam a prata do Novo Mundo, das suas minas da América do Sul. Mas como ficava muito caro atravessar o Pacífico com a prata, nunca foram concorrentes muito sérios.

Os outros concorrentes eram os Holandeses. Eles queriam ficar com o nosso comércio e, para o conseguir, atacaram Macau quatro vezes, no princípio do séc. XVII. Nunca conseguiram, mas estão a ver a tentação que constituía este comércio tão rentável.

Tudo isto é para explicar que o nosso povo, de alguma forma, teve sempre uma certa vocação comercial; diria mesmo que, ainda hoje, cá bem dentro de nós, talvez ela esteja um bocadinho esquecida, um bocado sepultada no tempo, mas têmo-la e penso que vale a pena olhar para ela de novo.

O proteccionismo industrial é um fenómeno que tem raízes históricas antigas. Já no tempo do Marquês de Pombal foram criados monopólios. Por exemplo, uma companhia, como a Vista Alegre (fundada um pouco mais tarde, isto é, em 1824), tinha o monopólio de certas loiças. Ainda hoje, em determinadas feiras rurais, se pode encontrar louça da Vista Alegre muito antiga.

Quando olhamos já para este século, durante o regime do Estado Novo, havia uma lei que era a Lei do Condicionamento Industrial, que assegurava protecção aos industriais. Era muito vantajosa para alguns que beneficiaram disso, para os industriais que lá estavam, mas tinha a desvantagem, a longo prazo, de não os exercitar num ambiente competitivo.

Outra consequência associada é que o consumidor era pouco exigente e pouco sofisticado: quando uma pessoa, em vez de ter duas ou mais alternativas tem apenas uma, intuitivamente acaba por não ser exigente.

Um dos sectores onde se pode observar isso é o da Banca em Portugal: este sector evoluiu muito, nos últimos 5, 10 anos. Lembro-me que as "bichas" nos Bancos eram um bocado chatas de aturar, mas eram suportadas, porque era assim que todos os Bancos funcionavam. Hoje, apesar de tudo, não é assim: há gestores de conta, há variadíssimos produtos financeiros, fícando o cidadão comum a ganhar por ser mais bem tratado nesse sector de serviços. Todo o proteccionismo anterior era bom para quem dirigia as empresas, mas de facto tornava os clientes pouco exigentes e isso, por sua vez, não espevitava as empresas.

Muitas vezes, as empresas olhavam para o seu mercado interno, focando o modo como iam conseguir procurar receitas para atingir o seu "break-even point" e olhavam o mercado externo de uma forma marginal. Ou seja, conseguiam assegurar no seu mercado interno as receitas necessárias para cobrir os custos fixos e depois exportavam mais alguns produtos a baixos preços, de forma a poderem ganhar mais algum dinheiro. É por isso que muitas vezes havia preços mais elevados no mercado interno e preços mais baixos no mercado externo, de artigos 
produzidos pelos mesmas empresas portuguesas. Tudo isto baseado num baixo nível de salários e numa certa miséria social e pessoal dos indivíduos, porque apostávamos numa tecnologia de baixo custo e depois vendíamos os produtos a baixo preço. É um pouco a lógica dos países do $3^{\circ}$ Mundo que ainda hoje predomina em muitos sectores.

Hoje o que se está a tentar fazer (é a grande aposta do governo português e de uma série de sectores) é transitar para uma nova maneira de fazer gestão e de operar nas empresas: é abandonar esta lógica de custo baixo que, de alguma forma, tem consequências sociais graves, para adoptar uma lógica de qualidade e de alto valor acrescentado que permita obter preços mais altos. Alguns sectores penso que o vão conseguir, outros não o conseguirão.

De qualquer maneira, citarei uma frase que o Prof. Michael Porter proferiu, numa conferência realizada em Espinho. Uma das coisas interessantes que ele disse acerca da integração na Comunidade Europeia é que, pelo facto de Portugal entrar nessa Comunidade não quer dizer que vamos ficar iguais em tudo a todos os países da Europa. Vamos tentar ficar iguais em termos de nível de vida e padrões sociais, agora em termos de actividades especializadas, de actividades competitivas é precisamente o contrário.

O que em princípio acontecerá na União Europeia é que cada país tentará encontrar os sectores onde faz produtos e serviços muito bem e depois irá trocá-los por bens produzidos por sectores eficientes de outros países da Comunidade. Portanto, um país pequeno como Portugal nunca poderá ter todos os sectores, apenas no seu espaço. Vai ter alguns cinco a dez sectores, nos quais é muito bom, criando empresas de gabarito europeu. Não haverá uma homogeneização da Comunidade a nível industrial, antes pelo contrário haverá talvez ainda mais especialização.

Quanto ao estudo de Michael Porter, ele está a tentar encontrar pistas. Alguns industriais não gostaram, o próprio Ministro da Indústria criticou os primeiros resultados mas, apesar de tudo, penso que ele tem uma perspectiva honesta. Era mais fácil dizer que nós iríamos ser a Califórnia da Europa, que iríamos fazer semicondutores, foguetões ou outros produtos de países muito desenvolvidos. Mas, curiosamente, os primeiros resultados apontam para muitos dos sectores tradicionais em que o nosso tecido industrial ainda continua a apostar.

Ele citou a história de uma empresa japonesa, nomeadamente o caso da Honda: hoje a Honda está implantada um pouco por todo o lado, até faz motores para a Fórmula 1.0 que não é tão conhecido é que o Sr. Honda, há alguns 50 anos atrás, a seguir ao pós-guerra, começou com a sua empresa vendendo bicicletas motorizadas, porque ele achava que aquelas colinas em Tóquio eram um bocado difíceis para se subirem a pé. Como os Japoneses utilizavam bicicletas, ele achou uma boa ideia introduzir uns motores muito simples, nem de $50 \mathrm{~cm}^{3}$ eram. A Honda arrancou aí, mais tarde introduziu motorizadas mais potentes, depois carros pequenos, 
depois carros maiores e hoje já está nos carros da Fórmula 1 e noutras linhas de produtos também.

As coisas não se constroem de um dia para o outro; esta é uma história de um homem e de um império empresarial que começou há mais de 50 anos. Não vale a pena ter sonhos, viver quimeras e dizer que daqui a 2 ou 3 anos os sectores portugueses estarão muito desenvolvidos. Mal ou bem e apesar das críticas que houve, Michael Porter revelou sempre uma postura honesta e realista.

Voltando ao início, o que é que eram as actividades do Marketing nesse tempo? Estamos a falar dos anos 30, 40 e 50, em que era fraca a exigência do consumidor. $O$ que é que eram os pontos de venda? Algo como os super e hipermercados não existiam, eram as Feiras e as pequenas mercearias. $O$ que era a atribuição dos preços? Era o velho regateiro tradicional das nossas Feiras. A qualidade do produto era muito heterogénea, não havia o conceito de imagem de marca a defender. Os produtos iam-se vendendo, não havia marcas e as embalagens muitas vezes não existiam.

Quando olhamos para a história das actividades comerciais em Portugal, foi talvez nas décadas de 50 e 60 (por altura do mini-boom que houve na economia do nosso país) que se deu o início da actividade comercial moderna. Nessa altura, vieram para Portugal uma série de multinacionais, muitas delas com presença em muitos países do mundo, como uma Lever, uma Nestlé.

Trouxeram conhecimentos de lá de fora e criaram uma coisa que foi importante: foram as verdadeiras escolas de Marketing no seio dessas empresas. Ainda hoje no nosso país, apesar de nas Universidades terem aparecido cursos de Gestão cada vez mais evoluídos e recentemente Mestrados, ainda há muito executivo que acha que, quando um jovem de 22 anos sai da Faculdade, a começar a sua carreira, na área comercial, deve escolher empresas como a Lever ou a Nestlé: estas são excelentes escolas de vida para aprender algumas coisas que a Faculdade não foi capaz de lhe ensinar. Essa ideia começou na década de 60, mais intensamente através dessas empresas, em que conceitos como lançamento de marcas, como a utilização mais intensiva da TV começaram a aparecer.

Também se começou a fazer um esforço de captação de mercados em que se procurou, de alguma forma, avaliar o comportamento do principal decisor dos produtos de consumo - a dona de casa. Muita da publicidade que desde então se faz é dirigida ao sexo feminino: são elas que decidem com mais peso o que se bebe, o que se come, que detergente usar, etc. e este aspecto não escapou às empresas.

Existem estudos muito interessantes que as próprias empresas fizeram, até acompanhando a própria evolução do conceito do que é que é ser dona de casa e do lar. Há, por exemplo, um estudo do princípio dos anos 60 da Nestlé, nos EUA. Quando se começaram a lançar as primeiras sopas "pré-fabricadas", não obtiveram grande resultado e procurou-se saber o porquê. Depois de uma série de estu- 
dos feitos, alguns até utilizando técnicas de psicologia clínica, chegou-se à conclusão que as mulheres se sentiam culpabilizadas por oferecerem esse tipo de sopas à família e portanto eram consideradas más donas de casa. A partir daí e ainda hoje, isso acontece nos anúncios actuais, aposta-se mais nos aspectos de desculpabilização da dona de casa do que propriamente nos aspectos ligados ao lado utilitário. O principal aspecto da cena que surge nos anúncios é uma família satisfeita e sorridente, em que aparece a terrina de sopa ("pré-fabricada") a fumegar, com um aspecto muito apetitoso e todos com um ar muito satisfeito, a fazerem comentários elogiosos.

A maior parte das grandes multinacionais apostaram em produtos de grande consumo, nos produtos do lar e não nos produtos industriais. Estes produtos ainda hoje estão pouco desenvolvidos em Portugal.

Ao longo da década de 60 , princípios da década de 70 , aos poucos e poucos começou a desenvolver-se uma série de actividades, por exemplo, de meios de comunicação. É no princípio da década de 70 que aparece o primeiro semanário especializado, o "Expresso". É também na década de 70 que aparece a $1 .^{a}$ empresa de placares exteriores, a J. C. Decaux.

O 25 de Abril veio fazer estalar uma crise na nossa sociedade. Penso que, apesar de tudo, para o aperfeiçoamento das actividades comerciais, a crise não foi má em termos qualitativos. A competição tornou-se maior e efectivamente o Marketing teve que se tornar mais especializado. Já não havia donas de casa, havia a dona de casa da $3 .{ }^{\mathrm{a}}$ idade e a dona de casa jovem sem filhos, a dona de casa com bébés para criar, a dona de casa de meia idade, etc. Portanto, de alguma forma começou-se a fazer uma certa segmentação mais apurada dos mercados, em que se procurava tentar satisfazer esse conjunto de quereres e de necessidades quotidianas de uma forma mais apurada.

Costumo dar, como exemplo, uma das nossas cozinhas modernas, enfim toda aquela panóplia de instrumentos que hoje existe, desde o frigorífico, micro-ondas até outras coisas mais ou menos complicadas. Uma cozinha moderna é tecnologicamente muito mais complexa do que uma fábrica da Revolução Industrial. Num espaço de $10 \mathrm{~m}^{2}-20 \mathrm{~m}^{2}$ temos hoje mais tecnologia do que há 200 anos tínhamos numa fábrica de milhares de metros quadrados. Tudo isso demonstra uma evolução do próprio papel da mulher que hoje já não quer ficar em casa, quer ter tempo para outras coisas, para além de cuidar do bebé, do marido e dos filhos, quer ter a sua vida, quer ter a sua empresa, quer ser estudante universitária. Para tudo isto ela tem que ganhar tempo para realizar todo esse conjunto vasto de tarefas.

Portanto, houve um papel que evoluiu e as empresas perceberam isso e tentaram adaptar-se aos novos produtos e serviços, como o pronto-a-comer, o pronto-a-vestir, que há 50 anos atrás não existiam e hoje são grandes indústrias. Há quem critique e ache que isso é um problema dos tempos modernos. Mas a verdade é que uma senhora já não está disposta a perder 3 horas a fazer uma sopa em 
casa e, portanto, vai ao pronto-a-comer que é mais prático, e dessa forma resolve os seus problemas.

Embora a década de 70 tenha sido um período de convulsão social e económica, foi realmente um período de enriquecimento interior dos homens do Marketing, na medida em que, sendo tudo mais competitivo, tiveram que encontrar novas formas de competir.

Outra ideia que apareceu nessa altura foi o Marketing Político, em princípio de uma forma muito crua, com as pinturas nas paredes, etc. Hoje o Marketing Político é uma área tão especializada como muitas outras e continuará a evoluir ainda mais.

Actualmente estão a fazer-se vários estudos; por exemplo, na última campanha de Bill Clinton nos EUA, basicamente ele seguia muito o que o seu Staff de Advisers lhe dizia. Em cada dia havia um estudo de mercado em que tentava captar a recepção da audiência para as suas propostas políticas.

Surge a década de 80. É uma década de mais optimismo por diversas razões: surge o prenúncio da entrada para a $\mathrm{CE}$ e a sua concretização.

Se antes da década de 70 havia ainda sectores mais ou menos protegidos pela Lei do Condicionamento Industrial do tempo de Salazar, viria depois a Lei das Nacionalizações do tempo do PREC. Basicamente a lógica era a mesma: a protecção de sectores inteiros da concorrência, o que teve como consequência não se tornarem mais competitivos. Adiaram-se medidas e mudanças de pessoas e foi por isso que mais tarde houve transições brutais, quando os sectores se abriram completamente ao exterior.

Hoje vêem-se as imagens da TAP que são dramáticas, com os trabalhadores a invadirem a pista e a darem-se vários confrontos. Tudo isso advém do facto de ter sido uma empresa protegida durante décadas e que hoje está a tentar apanhar o comboio, com alguns anos de atraso.

No fundo os Americanos já executaram uma reestruturação do sector há cerca de 5-10 anos atrás, algumas companhias europeias já o fizeram há 3-5 anos. Algumas companhias como a nossa ainda estão agora a começar.

A partir de certa altura realmente o que a sociedade pergunta é: será que a empresa deve permanecer não competitiva e toda a sociedade terá que pagar por um bilhete de avião o dobro do preço que poderia custar? Ou, pelo contrário, a empresa deve ser "emagrecida" e podendo assim o preço tornar-se próximo de um nível mais globalmente competitivo?

É no fundo um dilema social que não é fácil solucionar. São aqueles milhares de trabalhadores, por um lado, e os clientes a pedir os bilhetes mais baratos, por outro.

A questão é que as leis proteccionistas apenas adiam os problemas. É um bocado como aqueles elásticos que se vão esticando, mas algum dia saltam e alguém se magoa com isso: é o que acontece a um sector que adia a sua exposi- 
ção ao Mundo. Há um exemplo clássico de um país na Europa que é a Albânia, que se orgulhava de ter estado fechada durante décadas. Efectivamente, eles ficaram parados no tempo, a seguir ao após-guerra e agora, ao abrirem-se ao exterior com a queda do comunismo, vai ser um bocado complicado para eles fazerem a transição. A todos os países de Leste aconteceu exactamente o mesmo problema.

Convém dizer que o proteccionismo não é um problema de esquerda ou de direita, é um problema mais global. Quando este desaparece há uma transição brutal e depois é preciso bastante arte para gerir o processo.

$\mathrm{Na}$ década de 80 emergiram realmente novos fenómenos curiosos. Por um lado, os canais de distribuição alteraram-se radicalmente, aparecendo novas unidades ultra-modernas como os hipers. Eu lembro-me que no primeiro deles, o Continente, que abriu em 1985 em Alfragide na Amadora, era muito usual as pessoas irem com uma lista com 5 ou 10 itens para comprar e depois sairem com 2 carrinhos cheios. Era a magia dos preços baixos das actividades promocionais. Hoje as pessoas já estão "vacinadas", e já não acontece isto.

Outras unidades com cada vez mais peso são as unidades de Franchising. Portugal é um bom exemplo, temos o caso da Benetton já cá instalada, temos a nível português as próprias lojas da Cenoura que tiveram uma expansão internacional.

Aos poucos e poucos na década de 90, em Portugal, apareceram elementos de Marketing Directo. Ou seja, ao contrário das actividades comerciais clássicas, o produto vai ter com o cliente e não o cliente com o produto. O Marketing Directo actualmente em Portugal já envolve 2 ou 3 milhões de contos e tende a crescer enormemente. Nos EUA hoje é das actividades mais importantes de comercialização.

A outra mudança reside na própria dinâmica da evolução dos preços. Não há fixação tão rígida dos preços e o velho regateio está cada vez mais posto de lado. No entanto este faz-se a outros níveis, apesar das grandes superfícies o terem prejudicado. Em vez de ir a 10 mercearias e regatear meia hora com cada merceeiro, hoje vamos aos hipermercados onde temos vários preços e escolhemos o mais barato: há claramente uma evolução.

No panorama da comunicação empresarial, há uma evolução total. Não só a própria televisão evoluiu, hoje já temos 4 canais televisivos cada vez mais diferenciados e com personalidades diferentes. A própria rádio está cada vez mais especializada, os jornais, esses multiplicam-se, etc. Claramente, hoje a maneira de poder anunciar produtos pode ser muito especializada e muito mais sofisticada tecnicamente.

Finalmente na área do produto, eu diria que esta é a última das grandes áreas em que estamos mais atrasados em Portugal. Não é por acaso que o governo português, ao lançar por exemplo programas como o PAEP, de criação de marcas, está a fazer um grande esforço nesta área. Infelizmente os nossos produtos conti- 
nuam a ser indiferenciados, sem marcas, o que faz com que, quando tentamos vender no estrangeiro, conseguimos fazê-lo a baixo preço e, como consequência, isso acarreta baixos salários e uma certa miséria social nalgumas regiões do nosso país.

De alguma forma, o grande desafio, que hoje se coloca, é o de uma aposta num novo tipo de produtos mais baseados em valor e em qualidade do que no baixo custo. Até diria que na competição, em termos de baixo custo, não é preciso muito Marketing, o que é preciso é ter bons contabilistas, uns bons "controlers" que "martelem" os custos para baixo. Naturalmente um preço baixo decorre disso, e a partir daí consegue-se uma posição competitiva. Só que também temos o lado social da questão, são salários baixos, é uma certa miséria. Portanto, a nossa grande aposta neste momento, como país, não é ser a Califórnia da Europa, não vamos entrar nessas quimeras, porque isso é estar a enganarmo-nos a nós próprios.

Eu gosto de recordar uma história que o Prof. Xavier Pintado conta acerca da integração da Itália na $\mathrm{CE}$, em que os Italianos punham o seguinte dilema na década de 50, antes da adesão: "Será que vamos ser esmagados pelos Alemães?", perguntavam os industriais italianos do Norte. No fundo, entre Milão e Munique são duzentos e tal kms em linha recta. A verdade é que, após estes anos todos, o Norte de Itália que estava mais próximo da Alemanha (portanto teria mais medo da proximidade geográfica) está mais florescente, está bem de saúde, e o Sul, a Sicília e outras regiões da Itália Meridional continuam naquele atraso tradicional. Aparentemente, a capacidade de competir não depende tanto da proximidade geográfica como das capacidades das organizações e das pessoas.

É certamente este grande desafio que hoje se coloca à classe empresarial portuguesa, de modo que eu me atreveria agora a dar uma série de ideias, que têm aparecido ultimamente sobretudo nas empresas de sucesso dos anos 90 , neste ambiente global, mais competitivo, mais complicado e de maior exigência. Existem vários autores que basicamente sugeriram oito recomendações e que são as seguintes:

\section{$1 .^{a}$ - A ORIENTAÇÃO PARA OS NICHOS DE MERCADO}

Eu penso que isto é muito importante para Portugal, porque nós somos um país de pequenas empresas: mesmo os nossos grupos económicos, todos somados, são menores que uma multinacional de dimensão média europeia. Somos $3 \%$ em termos de população da Comunidade e em termos de PIB cerca de $1 \%$. Portanto nunca haveremos de ter empresas gigantes na Comunidade, que possam mudar sectores inteiros. $\mathrm{O}$ que podemos encontrar dentro de sectores inteiros são pequenos nichos de mercado, onde podemos ser especialmente competitivos e bem sucedidos.

Deixem-me dar um exemplo de um caso de sucesso de uma empresa portuguesa, que acho que é notável: a Sogrape com o seu Mateus Rosé. Eu sei que os 
Portugueses olham aquilo um bocado como um produto químico, e dizem, "isso não é bem vinho". Mas a verdade é que uma empresa portuguesa teve a capacidade de produzir um produto não natural, não há vinhas rosé por aí, e que atingiu a liderança para o segmento a que estava destinado.

$\mathrm{Na}$ orientação para os nichos de mercado, o fundamental é o elevado valor acrescentado, através de uma diferenciação especializada. Não é preciso dominar grandes sectores, basta um pequeno núcleo no meio de um grande mercado que pode ser extremamente rentável. Penso que isto é essencial para a pequena empresa portuguesa, que tem que saber onde quer estar e para onde quer ir. Esta é que é a ideia fundamental. Claro que tem que se fazer previamente um trabalho aprofundado de análise de mercados e de sectores. Tem que se perceber muito bem onde é que estão os elementos de valor, o que é que as pessoas querem. Esta realmente é que é a única solução possível, porque não temos recursos financeiros, logísticos, ou comerciais para ter uma posição dominante num sector inteiro.

Talvez um exemplo de excepção à regra que se possa aproximar mais disso é o caso das cortiças, mas porque temos um microclima que nos favorece. Aí, o grupo Amorim consegue ter uma posição próxima do domínio mundial, no sector da cortiça, mas esta situação deve ser caso único. Não sei se em Portugal há mais algum caso, mas não haverá assim muitos mais.

\section{$2 .^{\mathrm{a}}$ - QUALIDADE}

Hoje é um tema muito falado, mas deixem-me dizer duas ou três coisas acerca desta palavrinha. Antes falava-se na competitividade por preço e por custo. A palavra qualidade infelizmente é um conceito muito mais difícil de definir, porque a palavra qualidade tem mil caras, pode ter mil significados: qualidade em cortiça é diferente de qualidade na Banca, de qualidade em bacalhaus ou em outras coisas. E, realmente, o que é que está por detrás desta palavra que muda de sector para sector? Que pode mudar de cliente para cliente? Que pode mudar ao longo do tempo?

É um desafio muito mais complexo, mas também muito mais rentável, porque, se acertarmos em cheio, podemos ter margens mais elevadas. Apesar de tudo, independentemente do sector onde estamos a trabalhar ou o cliente, etc., há elementos fundamentais que são comuns.

O que conta é a qualidade percebida pelo cliente. Por vezes, certos técnicos ultra-especializados têm um conceito de qualidade que não está na cabeça do cliente; por vezes o técnico especializado não é a melhor pessoa para ajuizar. $O$ cliente quer uma coisa muito simples e o técnico está a pensar noutras coisas ultra-sofisticadas. Às vezes faz-me lembrar aquelas novas aparelhagens dos japoneses: eu costumo dizer, um bocado jucosamente, que produzem sons tão apura- 
dos que só o cão da vizinha consegue distinguir. São de uma grande qualidade técnica, mas quanto ao ponto de vista da qualidade comercial isso não é relevante: têm um som muito apurado mas o ouvido humano não chega lá. Portanto, na gestão de qualidade o que é fundamental é o que as pessoas percebem e não o que os técnicos dizem que é.

O segundo elemento importante é relativo às alternativas oferecidas pela competição. Ou seja, o jogo da competição da qualidade é um jogo que nunca mais vai acabar: hoje estamos a fazer campanha de aumento de qualidade mas, se os nossos concorrentes também fizerem o mesmo, dão um passo à frente e ficamos todos na mesma. Portanto, é um jogo que em princípio nunca irá terminar, de uma forma ou de outra.

\section{3. ${ }^{\mathrm{a}}$ - INOVAÇÃO}

O que é importante aqui ver é que, antes da tecnologia, existem as pessoas a quem as inovações se dirigem. Portanto, mais uma vez, a inovação não é aquilo que os homens de bata branca pensam.

Há um livro muito interessante chamado As fontes da Inovação, em que o seu autor, Von Hippel, procurava analisar múltiplos sectores de onde provinham as inovações e quais eram as bem ou as mal sucedidas. Ele tinha várias fontes, como por exemplo os tais técnicos, os tais homens de bata branca, os consumidores, a empresa, a força de vendas, etc. e chegou à conclusão que, efectivamente, as inovações mais rentáveis eram aquelas que vinham de sugestões feitas pelos consumidores e não aquelas que mudavam o mundo. As que mudavam o mundo eram realmente as feitas pelos homens de bata branca, que inventavam os conceitos mais ou menos revolucionários e daí a 20 ou 30 anos poderíamos ter um mundo diferente. No entanto eram muito arriscadas.

Do ponto de vista comercial (e isto é importante para a nossa pequena empresa que muitas vezes nem tem capacidade para pagar a esses homens de bata branca), é que a pequena empresa também pode inovar, basta estar atenta ao que os clientes querem e ir, aos poucos e poucos, de uma forma contínua, introduzindo certos melhoramentos.

Assim, a inovação não é obrigatoriamente algo descontínuo; pode ser um processo contínuo, muito lento, mas que permita uma penetração efectiva nos mercados.

\section{4. ${ }^{a}$ - CAPACIDADE DE RESPOSTA RÁPIDA}

Hoje, mais do que tudo, os mercados estão em constante mutação. Voltando mais uma vez ao tempo dos Descobrimentos, quando o nosso rei dava uma ordem ao vice-rei da Índia, ele, quando muito, daí a dois anos sabia o resultado: a nau 
levava um ano a lá chegar e um ano para voltar com a resposta. Eram uns tempos mais lentos, mais pacatos. Hoje, realmente, somos uma aldeia global, uma aldeia pequenina em que alguns mercados funcionam 24 horas por dia, como os mercados financeiros. Cada vez estamos mais próximos uns dos outros, quer devido às estradas, quer devido às tecnologias da comunicação. Assim, a capacidade de resposta rápida é cada vez mais importante.

As empresas não podem estar à espera que resolvam os problemas por elas, seja a UE, seja o governo, seja outra entidade qualquer. Cada vez mais as pessoas têm que confiar em si próprias e andar para a frente, porque hoje o jogo empresarial é muito mais acelerado do que era antes.

\section{$5 .{ }^{\mathrm{a}}-$ SERVIÇO}

Hoje há um autor que afirma que já não existe Marketing de Produtos, só existe Marketing de Serviços. Em nossos dias as ofertas das firmas são mais completas, são um aglomerado de várias coisas, podendo ser objectos, mas também são actividades locais, etc. Portanto, a componente humana hoje é essencial, porque as pessoas já não se contentam em receber por exemplo uma máquina de lavar, querem as instruções bem feitas, querem uma operação de demonstração, querem um bom serviço técnico pré e pós-venda, etc. Cada vez mais a área de serviço é um elemento primordial nas sociedades pós-industriais.

Houve vários sectores de serviços completamente novos que se criaram. Falamos no pronto-a-vestir ou no pronto-a-comer, como exemplos. Mesmo nos tradicionais produtos de consumo, o elemento serviço é cada vez mais utilizado como um elemento diferenciador e como uma componente cada vez mais importante de valor.

\section{$6 .^{\mathrm{a}}$ - ELEMENTO HUMANO}

Os homens são as máquinas de uma empresa de serviços. E enquanto as velhas máquinas dos sectores industriais continuam a evoluir (e hoje há avanços tecnológicos cada vez mais sofisticados), eu diria que, onde há mais por fazer, não é tanto no desenvolvimento das máquinas, onde desde o século XVIII já tivemos avanços espantosos, é essencialmente na gestão das pessoas, no seu entrosamento harmonioso, tanto do ponto de vista psicológico, de condições de trabalho, como do ponto de vista de entrosamento com o cliente.

$\mathrm{Na}$ área dos serviços a gestão de pessoal e a gestão comercial confundem-se: quando um empregado atrás do balcão atende mal algum cliente, a gente pode interrogar-se se isto é um problema comercial ou um problema de gestão de recursos humanos. Eu diria que é, simultaneamente, uma e outra coisa: temos um problema de enquadramento de recursos humanos e também um problema comercial 
porque está danificada a relação com um cliente. $O$ treino e a educação são cada vez mais importantes para as modernas sociedades pós-industriais. Não é por acaso que uma das prioridades do governo português é a efectiva melhoria do nosso capital humano, é a aposta na educação.

Lembro-me de ver há cerca de um ano atrás, num semanário, um conjunto de dados estatísticos sobre os países da Comunidade... no princípio deste século. Um número, que me chamou muito a atenção, foi o grau de escolaridade nos diferentes países que hoje são a UE: em 1900 o país que tinha maior nível de escolaridade era a Alemanha, já nessa altura mais de $90 \%$ de escolaridade básica. Eu penso que isto explica muito porque é que a Alemanha, apesar de todas as convulsões que causou a si própria e ao mundo, continua hoje a ser um dos países mais desenvolvidos da UE. Fizeram uma aposta incessante na qualidade e melhoria do seu capital humano e no treino a todos os níveis, inclusivamente a nível universitário. Criaram excelentes universidades e educação contínua a todos os níveis, na fábrica, nos escritórios, etc.

Portanto, aqui há muito que fazer. Infelizmente em Portugal esta é uma das áreas em que nós já estávamos na cauda da Europa nessa altura e hoje as coisas não melhoraram, em termos relativos. Quando olhamos para nós próprios, estamos muito melhor do que há 20 anos mas, comparando com a Comunidade, o nosso nível de escolaridade continua atrás do dos outros. Portanto há que valorizar os homens para poder melhorar as empresas. Isso vai acontecer de uma forma ou de outra, até porque, se não for assim, mais tarde ou mais cedo os estrangeiros virão para cá ocupar os nossos melhores lugares nas empresas. Não basta um salário baixinho, temos que ser mais eficientes, mais competitivos e aumentar essa capacidade do elemento humano no nosso país.

\section{7. ${ }^{a}$ - ACHATAMENTO DAS ORGANIZAÇÕES}

Quando uma organização não tem que competir, normalmente tende a não ter grande controlo nos custos, tende a alargar-se, tende a engordar.

Claramente o estilo de organização e a sua eficiência são muito importantes. Temos é que encontrar para cada pessoa uma função que a satisfaça de uma forma produtiva. Não é fácil, mas é necessário, porque caso contrário temos a tendência de criar Staff atrás de Staff, gente atrás de gente que se vai acumulando, que se vai atropelando e que vai criando cada vez mais problemas. Quando olhamos para certos tipos de organizações clássicas verificamos que eles eram muito mais escorreitos de que propriamente muitas organizações modernas. Havia uma classe dirigente, de topo, havia uma classe de contramestres ou sargentos, depois havia uma classe baixa de operários, de executantes. Hoje a tendência moderna é precisamente o retorno, o menor número de escalões hierárquicos. Caso contrário, se uma ordem vem lá de cima e tem que passar por 10 indíviduos por ali abaixo, 
chega cá abaixo deturpada, chega fora de horas, cheia de conflitos políticos e por vários canais: tudo isto se traduz numa disfunção enorme.

Hoje há realmente uma tendência para haver o tal achatamento, de modo a criar mais operacionalidade. Tem que haver contactos mais estreitos e rápidos entre os homens que comandam e os homens que obedecem.

\section{8. ${ }^{a}$ - LIDERANÇA INDIVIDUAL}

Eu acho que, neste mundo, qualquer que seja a organização de sucesso de alguma forma teve que ter um líder, teve que haver alguém que as outras pessoas seguissem. Apesar dos grandes projectos também serem fruto de grandes equipas, há sempre alguém, um homem ou uma mulher (normalmente mais homens, que essas coisas são tipicamente masculinas, mas também há alguns casos de mulheres célebres na história) que, com características pessoais de paixão, de persistência de poder, conseguiu levar os outros atrás de si. O nosso tecido empresarial está cheio dessas histórias de homens, alguns até com fraca educação, mas que conseguiram singrar e construir grandes organizações.

Apesar deste mundo cada vez mais tecnocrático, eu não podia deixar de terminar sem mais uma vez salientar o elemento humano. É muito complicado porque nós vivemos num mundo cada vez mais complexo e em constante mudança. Assim, é cada vez mais necessário haver os tais timoneiros que levem os barcos, nestes mares revoltados que são as sociedades pós-industriais modernas. É necessário que haja homens que sejam instintivamente seguidos por outros homens. 